NOTA

\title{
EFEITO DE ÉPOCAS DE SEMEADURA E ESTABILIDADE DE HÍBRIDOS DE MILHO EM PLANTIOS DE SAFRINHA NO NOROESTE DO PARANÁ(1)
}

\author{
ANDRÉ C. GARCIA VILHEGAS ${ }^{(2)}$; PEDRO SOARES VIDIGAL FILHO ${ }^{(3,4)}$; \\ CARLOS ALBERTO SCAPIM ${ }^{(3,4)}$; MARIA CELESTE GONÇALVES-VIDIGAL ${ }^{(3,4)}$; \\ ALESSANDRO DE LUCCA E BRACCINI ${ }^{(3,4)}$; EDVALDO SAGRILO ${ }^{(2)}$

\section{RESUMO}

Foram realizados ensaios com o objetivo de avaliar a estabilidade produtiva de híbridos de milho, em diferentes épocas de plantio, no período outono-inverno, em São Jorge do Ivaí, noroeste do Paraná. A primeira fase experimental, realizada no ano de 1996, constituiu-se na avaliação de 12 híbridos comerciais, utilizando-se o delineamento em blocos completos casualizados, com quatro repetições. Na segunda fase experimental, no ano de 1997, foram avaliados em cinco épocas de semeadura, com intervalo de 15 dias, os híbridos C 806, FT 9043, AG 5011, C 435 e C 701, que se destacaram na primeira fase de avaliação, com cada época de semeadura constituindo um ensaio distinto de competição. A análise conjunta envolvendo as diferentes épocas permitiu concluir que épocas de semeaduras tardias resultaram na redução linear da altura de planta e na redução quadrática da área foliar, não afetando, porém, a prolificidade e o número de folhas por planta. A produção de grãos, influenciada pela precipitação pluvial, apresentou tendência cúbica para todos os híbridos nos ensaios das diferentes épocas. O genótipo AG 5011 apresentou-se estável e produtivo, pelos métodos de Kang e Lin e Binns. Palavras-chave: Zea mays L., época de semeadura, estabilidade de produção.

\section{ABSTRACT \\ EFFECT OF SOWING TIMES AND YIELD STABILITY OF CORN HYBRIDS CULTIVATED DURING THE AUTUMN-WINTER PERIOD IN THE NORTHWEST OF PARANÁ STATE}

\begin{abstract}
Investigations were carried out with the objective of evaluating the yield stability of corn hybrids in different sowing times, during the autumn-winter season in São Jorge do Ivaí, State of Paraná, Brazil. In the first experiment 12 commercial hybrids were evaluated in randomized complete blocks design, with four replications. In the second, hybrids C 806, FT 9043, AG 5011, C 435 and C 701, selected in the first evaluation, were sown during 15 days interval and evaluated. The joint analysis involving different planting times allowed to conclude that the delayed sowing time resulted in a linear decrease in plant height and a quadratic decrease in leaf area, not affecting, however, the prolificity and the number of leaves per plant. The grain production, influenced by the water precipitation, showed cubic tendency for all hybrids in the trials of different sowing times. The genotype AG 5011 showed higher stability and yield by the classification of Kang and of Lin and Binns methods.
\end{abstract}

Key words: Zea mays L., sowing time, yield stability.

${ }^{1}$ ) Recebido para publicação em 25 de maio de 1999 e aceito em 9 de janeiro de 2001.

$\left(^{2}\right)$ Programa de Pós-Graduação em Agronomia, Universidade Estadual de Maringá (UEM), Av. Colombo, 5.790, 87020-900 Maringá (PR). E-mail: pga@uem.br

(3) Departamento de Agronomia, Universidade Estadual de Maringá (UEM).

$\left({ }^{4}\right)$ Com bolsa de produtividade em pesquisa do CNPq. 


\section{Introdução}

A cultura do milho no Brasil apresenta forte dispersão geográfica, coincidindo a época tradicional de plantio nas áreas em que a cultura é explorada comercialmente em larga escala, com o período de verão, cujas semeaduras são efetuadas nos meses de agosto a novembro (GOMES, 1991). Recentemente, devido a frustrações dos agricultores com as culturas de inverno, principalmente em relação ao trigo, cresceu o plantio extemporâneo do milho safrinha, cuja semeadura é efetuada no período de fevereiro a abril (CoRRÊA et al., 1997). A semeadura do milho safrinha, por ser efetuada em um período em que as condições climáticas são desfavoráveis ao desenvolvimento dessa cultura, é caracterizada pela utilização, entre os produtores, de tecnologia de baixo custo, tais como, segunda geração de híbridos, plantio sem adubação, com aproveitamento apenas dos resíduos da cultura anterior, e controle mecânico de plantas daninhas, o que resulta em menor produtividade. Persiste ainda a carência de informações adequadas sobre as recomendações de cultivares de milho preferenciais para cada região, bem como acerca do período mais adequado de semeadura nessa época de cultivo (DURÃEs, 1993).

Durante o período de crescimento da planta de milho, variações climáticas podem ocasionar alterações em diversas características da planta, destacando-se os componentes de rendimento, os quais, por sua vez, ao sofrerem alterações irão influenciar no rendimento final de grãos (COSTA, 1994).

Diversos trabalhos demonstram que, à medida que se retarda a semeadura do milho, a partir da época considerada preferencial para uma dada região, ocorre diminuição na produção de grãos em função da variação nos elementos climáticos, tais como precipitação, radiação solar e temperatura (Noldin, 1985; SouZA, 1989; Costa, 1994).

Variações no comportamento de genótipos de milho quanto às reações a diferentes estresses do ambiente têm sido evidenciadas em diversos estudos (Noldin, 1985). Além da importância da época de semeadura, a escolha correta de híbridos a serem cultivados pode representar acréscimo substancial na produção final (GERAGE et al., 1984). A época de semeadura, denominada safrinha, por representar situação não convencional, requer ajuste dos componentes genéticos às variações ambientais (MIRANDA FILHO, 1995). Assim, a ocorrência de condições climáticas desfavoráveis no período outono-inverno, associada às variações do comportamento de diferentes genótipos de milho em função da época de cultivo, justificam a realização deste estudo.
O presente trabalho tem por objetivo estudar a estabilidade de produção de híbridos comerciais de milho cultivados no período outono-inverno, em diferentes épocas de semeadura, na Região Noroeste do Estado do Paraná.

\section{Material e métodos}

No ano de 1996 foram conduzidos experimentos com o objetivo de avaliar o comportamento de 12 híbridos comerciais de milho. Destes, selecionaramse os híbridos C 806 (grão semiduro, alaranjado, superprecoce), C 435, C 701, FT 9043 e AG 5011 (grão semiduro, alaranjado, precoce), os quais foram avaliados no ano seguinte em cinco épocas de semeadura espaçadas de 15 dias, no período outono-inverno, com início em 6 de fevereiro de 1997, em São Jorge do Ivaí, noroeste do Estado do Paraná. A região apresenta altitude de $502 \mathrm{~m}$, clima subtropical (Cfa) com temperaturas médias, nos meses mais quentes, acima de $22{ }^{\circ} \mathrm{C}$, verões quentes, geadas pouco freqüentes, com tendência à concentração das chuvas nos meses de verão, não ocorrendo, assim, uma estação seca definida. A precipitação pluvial do período experimental encontra-se na figura 1.

O estudo do comportamento dos híbridos em cada época de semeadura envolveu ensaios distintos de competição, utilizando o delineamento experimental de blocos completos casualizados, com quatro repetições. Cada parcela constituiu-se de quatro fileiras de $9 \mathrm{~m}$ de comprimento, em que as duas laterais e $0,50 \mathrm{~m}$ de cada extremidade das mesmas configuraram-se em bordadura. Utilizou-se o espaçamento de $0,90 \mathrm{~m}$ entre fileiras e de $0,24 \mathrm{~m}$ entre plantas, resultando em área total de $28,8 \mathrm{~m}^{2}$ por parcela e $12,6 \mathrm{~m}^{2}$ de área útil. Foram avaliadas as seguintes características: altura de planta, prolificidade, número de folhas por planta, área foliar, massa de mil

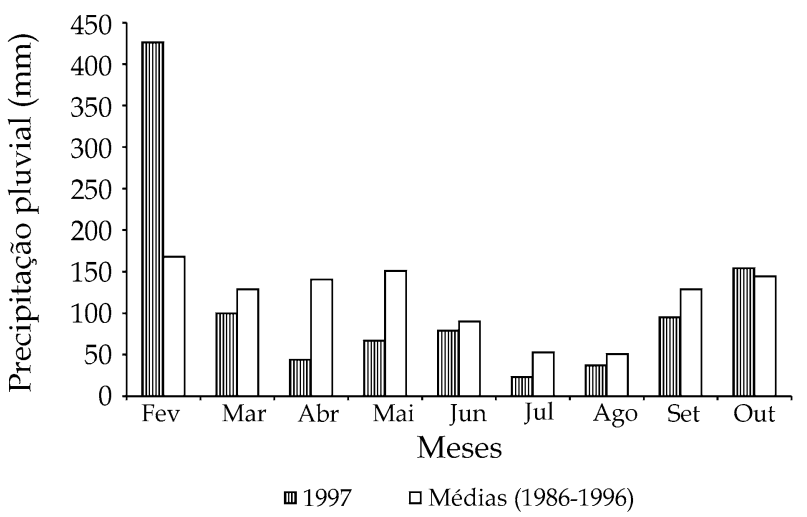

Figura 1. Precipitação pluvial (mm) durante a condução dos ensaios de épocas de semeadura de híbridos de milho e média pluvial de dez anos (1986 - 1996), no período outonoinverno, São Jorge do Ivaí (PR), 1997. 
grãos, produção de grãos e percentual de grãos ardidos. Inicialmente efetuou-se a análise de variância para cada um dos caracteres estudados nas diferentes épocas de semeadura, e, em seguida, procedeu-se à análise conjunta. Nesse agrupamento foram utilizados os experimentos cujos quadrados médios residuais não ultrapassaram a relação aproximada de 7:1 (GOMEs, 1990), sendo, dessa forma, consideradas todas as épocas de semeadura. Quando da interação significativa épocas de semeadura $x$ híbridos, procederam-se aos desdobramentos convencionais. Para avaliar o comportamento das características, em função das épocas de semeadura para cada híbrido, empregou-se a análise de regressão por meio de polinômios ortogonais (GOMEs, 1990). Estudou-se, também, a estabilidade de produção dos genótipos, utilizando-se os métodos de Plaisted e Peterson (1959) que se baseiam em análise de variância, de LiN e BinNS (1988) e de KANG (1988), considerados métodos não-paramétricos.

Optou-se por tais métodos, em detrimento dos que se baseiam em análise de regressão linear simples, pelos motivos apresentados por HueHN (1990). Basicamente, o autor afirma que o uso de medidas nãoparamétricas reduz ou evita a tendenciosidade causada por pontos completamente fora da equação de regressão ajustada e dispensa qualquer hipótese sobre a distribuição dos valores fenotípicos. Além disso, essas medidas são de fácil utilização e interpretação, não apresentando grandes variações nas estimativas, como poderia ocorrer com os métodos paramétricos de estimativa de estabilidade. Os métodos serão descritos da seguinte forma:

\section{Método proposto por Plaisted e Peterson (1959)}

O método proposto por Plaisted e Peterson (1959) quantifica a contribuição relativa de cada genótipo para a interação genótipos $\mathrm{x}$ ambientes e identifica aqueles de maior estabilidade.

Sua estimativa foi obtida pela expressão:

$$
\theta_{i}=\frac{1}{\mathrm{~g}-1}\left[\sum_{\mathrm{i}^{\prime}} \hat{\sigma}_{g a_{i i^{\prime}}}^{2}\right]\left(i \neq i^{\prime}\right)
$$

Sendo $d_{i i^{\prime}}^{2}$ o quadrado da distância euclidiana entre os genótipos $i$ e $i^{\prime}$, e com base no seu comportamento destes em $a$ ambientes, tem-se:

$$
d_{i i^{\prime}}^{2}=\sum_{j}\left(Y_{i j}-Y_{i^{\prime} j}\right)^{2}(j=1,2, \ldots, a)
$$

Dessa forma, deduz-se que:

$$
S Q\left(G_{i i} \times A\right)=\frac{r}{2}\left[d_{i i^{\prime}}^{2}-\frac{1}{a}\left(Y_{i .}-Y_{i^{\prime} .}\right)^{2}\right]
$$

Assim, tem-se que:

$$
\hat{\sigma}_{g a_{i i^{\prime}}}^{2}=\frac{\left[\frac{S Q\left(G_{i i^{\prime}} \times A\right.}{(a-1)}\right]-Q M R}{r}
$$

Pode-se calcular ainda a contribuição relativa de cada cultivar para a interação, pela seguinte expressão:

$$
\theta_{i}(\%)=\frac{\theta_{i} 100}{g \hat{\sigma}_{g a_{i i^{\prime}}}^{2}}
$$

\section{Método proposto por Lin e Binns (1988)}

Este método constitui boa alternativa na avaliação da estabilidade, pois possibilita a identificação de uma ou mais cultivares com desempenho próximo ao máximo, nos vários ambientes testados.

A estimativa do parâmetro de estabilidade é dada por:

$$
P_{i}=\frac{\sum_{j=1}^{n}\left(X_{i j}-M_{j}\right)^{2}}{2 n}
$$

em que:

$P_{i}$ : índice de superioridade da i-ésima cultivar; local;

$X_{i j:}$ produtividade da i-ésima cultivar no j-ésimo

$M_{j}$ : resposta máxima obtida entre todas as cultivares no j-ésimo local;

$n$ : número de locais.

A expressão pode ser desdobrada em:

$$
P_{i}=\frac{\left[n\left(\bar{X}_{i}-\bar{M}\right)^{2}+\sum_{j=1}^{N}\left(X_{i j}-\bar{X}_{i}-M_{j}-\bar{M}\right)^{2}\right]}{2 n}
$$

sendo:

$$
\begin{aligned}
& \bar{X}_{j}=\sum_{j+1}^{n} \frac{X_{i j}}{n} \\
& \bar{M}=\sum_{j+1}^{n} \frac{M_{j}}{n}
\end{aligned}
$$

em que:

$\bar{X}_{j}$ refere-se à média das produtividades das cultivares obtidas nos $n$ ambientes;

$\bar{M}$ refere-se à média das respostas máximas de todas as cultivares em todos os ambientes.

Em razão da estatística $P_{i}$ ser o quadrado médio da distância em relação à resposta máxima de cada ambiente, e não a distância simples, ela tem propriedade 
de variância, ou seja, pondera pelos desvios de comportamento das cultivares ao longo dos ambientes ou, ainda, considera a estabilidade de comportamento.

\section{Método proposto por Kang (1988)}

KANG (1988) trabalhou, originalmente, com a estimativa de estabilidade proposta por SHUKLA (1972). No presente trabalho está-se modificando tal método, empregando-se a estimativa $\theta_{i}$ de Plaisted e Peterson (1959) e as médias gerais de produção de grãos.

Inicialmente procedeu-se à classificação dos genótipos em ordem decrescente, quanto às médias de produção, ou seja, foi adotado valor 1 para o genótipo mais produtivo, valor 2 para o segundo, e assim por diante. Posteriormente, foi feita a classificação em ordem crescente, com base no estimador de Plaisted e Peterson (1959), ou seja, foi adotado valor 1 para a menor estimativa de estabilidade, valor 2 para a segunda menor, e assim sucessivamente.

A seguir, procedeu-se à soma de classificações, obtendo-se a estimativa do parâmetro de estabilidade de KANG (1988), em que a menor soma encontrada foi considerada o genótipo mais estável e produtivo.

\section{Resultados e Discussão}

Os resultados da análise de variância conjunta envolvendo as cinco épocas de semeadura avaliadas revelaram diferenças significativas $(\mathrm{P} \leq 0,05)$ para os híbridos, épocas de semeadura e para a interação híbridos x épocas de semeadura, nas seguintes características: massa de mil grãos, produção de grãos e percentagem de grãos ardidos. A significância da interação híbridos x épocas de semeadura indica, para tais variáveis, que o comportamento dos híbridos não foi coincidente nas diferentes épocas de semeadura.
Verificou-se, também, que a interação híbridos x épocas de semeadura foi não-significativa $(P>0,05)$ para as características altura de planta, prolificidade, número de folhas por planta e área foliar. Assim, pode-se deduzir que o comportamento dos híbridos foi coincidente nas diferentes épocas de plantio para essas características. Observou-se que a defasagem na semeadura afetou, de maneira linear decrescente, a altura das plantas (Quadro 1). A redução na altura final das plantas, em função da época de semeadura, também foi observada por Souza (1989) e CostA (1994).

Para a variável prolificidade dos diferentes híbridos estudados, verificou-se que a mesma não foi influenciada pela época de semeadura. Os índices de prolificidade encontrados foram inferiores a 1,0, fato que caracteriza os híbridos estudados como nãoprolíficos (Quadro 1). Vale ressaltar que o caráter prolificidade sofre grande influência das condições ambientais e, portanto, é possível que em ambiente mais favorável tais híbridos venham a apresentar comportamento diferenciado.

A defasagem nas semeaduras dos diferentes híbridos não influenciou significativamente o número de folhas por planta (Quadro 1). Trabalhos realizados por Costa (1994), pesquisando 15 épocas de semeadura espaçadas de 30 dias e iniciadas a partir do mês de novembro, em Viçosa (MG), mostraram diferenças significativas para o número de folhas por planta, ao longo das épocas de semeadura. Outros trabalhos demonstram a influência da temperatura sobre o número de folhas, provocando aumento geral do número de folhas, em resposta à elevação da temperatura média diária entre 15 e $30^{\circ} \mathrm{C}$ (TollenaAr et al., 1979). Por outro lado, alguns trabalhos revelam

Quadro 1. Valores médios relativos aos caracteres altura de planta (AP) em metros, prolificidade (P), número de folhas por planta (NF) e área foliar (AF) em $\mathrm{dm}^{2}$

\begin{tabular}{|c|c|c|c|c|c|c|c|c|c|c|c|c|c|c|c|c|c|c|c|c|}
\hline \multirow{3}{*}{ Híbridos } & \multicolumn{20}{|c|}{ Épocas de semeadura } \\
\hline & \multicolumn{4}{|c|}{1} & \multicolumn{4}{|c|}{2} & \multicolumn{4}{|c|}{3} & \multicolumn{4}{|c|}{4} & \multicolumn{4}{|c|}{5} \\
\hline & $\mathrm{AP}$ & $\mathrm{P}$ & NF & $\mathrm{AF}$ & $\mathrm{AP}$ & $\mathrm{P}$ & NF & $\mathrm{AF}$ & $\mathrm{AP}$ & $P$ & $\mathrm{NF}$ & $\mathrm{AF}$ & $\mathrm{AP}$ & $\mathrm{P}$ & $\mathrm{NF}$ & $\mathrm{AF}$ & $\mathrm{AP}$ & $\mathrm{P}$ & NF & $\mathrm{AF}$ \\
\hline C 806 & 1,77 & 0,98 & 10,3 & 450,3 & 1,51 & 0,92 & 9,5 & 514,6 & 1,47 & 0,95 & 11,0 & 487,3 & 0,95 & 0,88 & 8,8 & 270,5 & 0,65 & 0,81 & 9,8 & 161,8 \\
\hline FT 9043 & 1,64 & 0,95 & 10,5 & 469,4 & 1,16 & 0,87 & 10,8 & 460,9 & 1,21 & 0,86 & 10,8 & 511,8 & 0,81 & 0,91 & 9,5 & 233,7 & 0,48 & 0,58 & 8,8 & 191,0 \\
\hline AG 5011 & 1,66 & 0,98 & 10,5 & 476,1 & 1,28 & 0,90 & 10,8 & 475,2 & 1,33 & 0,81 & 10,8 & 507,1 & 0,91 & 0,95 & 10,8 & 274,5 & 0,70 & 0,81 & 10,0 & 218,2 \\
\hline C 435 & 1,69 & 0,97 & 10,0 & 452,1 & 1,32 & 0,85 & 10,8 & 492,5 & 1,45 & 0,68 & 11,0 & 508,0 & 0,95 & 0,92 & 9,8 & 214,7 & 0,68 & 0,65 & 9,8 & 247,9 \\
\hline C 701 & 1,71 & 0,94 & 10,3 & 511,1 & 1,30 & 0,90 & 10,8 & 452,5 & 1,49 & 0,81 & 10,3 & 492,3 & 0,93 & 0,95 & 9,3 & 250,3 & 0,70 & 0,52 & 9,3 & 190,2 \\
\hline Médias & 1,69 & 0,96 & 10,3 & 471,1 & 1,31 & 0,89 & 10,5 & 479,1 & 1,39 & 0,82 & 10,8 & 501,3 & 0,91 & 0,92 & 9,6 & 248,7 & 0,64 & 0,67 & 9,5 & 201,8 \\
\hline C.V. (\%) & 2,27 & 1,88 & 9,1 & 2,5 & 6,45 & 8,37 & 6,6 & 7,2 & 6,24 & 9,96 & 8,5 & 9,8 & 5,06 & 4,48 & 6,6 & 10,7 & 19,53 & 31,89 & 7,4 & 21,3 \\
\hline
\end{tabular}

Época 1 =6/2/1997; Época 2 =21/2/1997; Época 3 =8/3/1997; Época $4=28 / 3 / 1997 ;$ Época 5 =8/4/1997. 
que o aumento na temperatura pode resultar na diminuição do número de folhas (WARRINGTON e KANEMASU, 1983). Assim, para este estudo, as condições ambientais prevalecentes no período de condução dos ensaios não contribuíram para afetar o número de folhas formadas pela planta do milho.

$\mathrm{O}$ efeito da defasagem das semeaduras para o caráter área foliar (AF) apresentou comportamento quadrático com o máximo da função em $489 \mathrm{dm}^{2}$ por planta. Posteriormente a área foliar decresceu, apresentando, na quarta e na quinta época, valores de $248,73 \mathrm{dm}^{2}$ e $201,80 \mathrm{dm}^{2}$, por planta respectivamente (Quadro 1). Essa redução de área foliar pode ter sido ocasionada por estresse hídrico, ocorrido durante o desenvolvimento vegetativo das plantas (Figura 1).

Em relação à produção de grãos $(\mathrm{PG})$, o efeito da época de semeadura para cada híbrido avaliado pode ser melhor observado por meio das regressões apresentadas na figura 2. Nota-se que a época de semeadura provocou variação na produção de grãos, que se ajustou a um modelo cúbico para todos os híbridos avaliados. De modo geral, todos os híbridos apresentaram as maiores produções nas épocas 1, $3 \mathrm{e}$ 4 , e, as menores, nas épocas 2 e 5 (Quadro 2). Isso pode ser explicado pelas condições climáticas registradas nesses períodos de semeadura, principalmente no que se refere à precipitação pluvial (Figura 1). O atraso na época de semeadura de milho, dentro da estação de crescimento, normalmente ocasiona decréscimo na produção de grãos (NolDIN, 1985; SouZA, 1989; COSTA, 1994). Vários autores relatam que a redução no rendimento de grãos de milho semeado em épocas tardias, tem sido associada a fatores climáticos, especialmente radiação solar e temperatura. Segundo Souza (1989), o fator climático que mais contribui para o efeito prejudicial do atraso do plantio

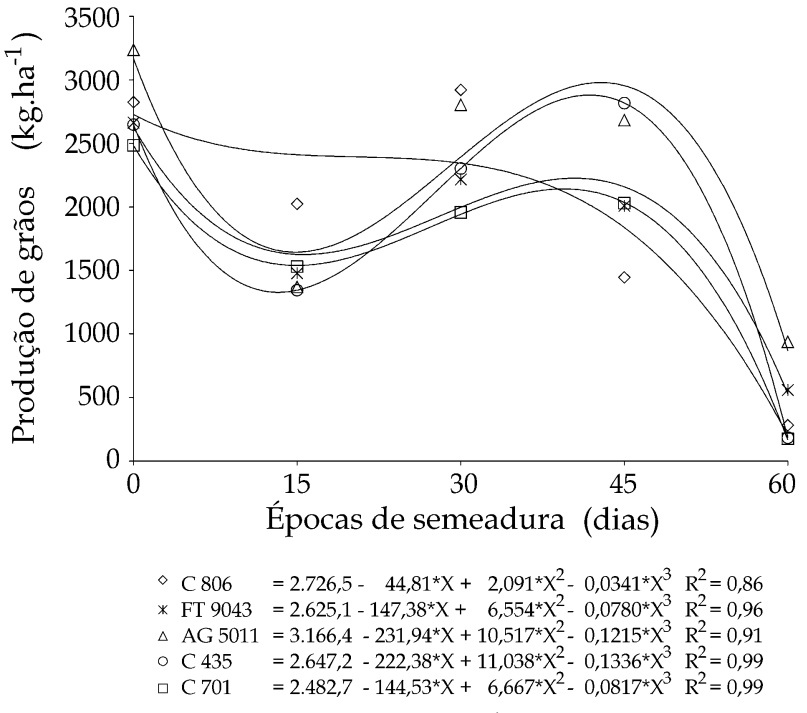

Figura 2. Produção de grãos $\left(\mathrm{kg} \cdot \mathrm{ha}^{-1}\right)$ de cinco híbridos de milho, em função do número de dias após a primeira semeadura. São Jorge do Ivaí-PR. 1 = 6/2 /1997; 2 = 21 / 2/1997; $3=8 / 3 / 1997 ; 4=23 / 3 / 1997 ; 5=8 / 4 / 1997$.

* significativo, em nível de $5 \%$ de probabilidade, pelo teste t.

é a redução da precipitação pluvial nos estágios mais críticos da cultura, isto é, no florescimento e no enchimento de grãos. A produção de grãos da segunda época de semeadura $(21 / 2 / 97)$ foi inferior à terceira e à quarta época, mesmo com área foliar superior (Quadro 1), devido ao fato de o florescimento masculino ter ocorrido na segunda quinzena do mês de abril, período que coincidiu com baixas precipitações pluviais (Figura 1). De acordo com ToMMASelli e Villanova (1994), os períodos em que se observam as mais elevadas associações entre os rendimentos e as variáveis hídricas são os que englobam a floração e o início de enchimento de grãos, caracteri-

Quadro 2. Valores médios relativos aos caracteres produção de grãos (PG) em kg.ha ${ }^{-1}$, massa de mil grãos (MMG) em gramas e grãos ardidos em \%

\begin{tabular}{|c|c|c|c|c|c|c|c|c|c|c|c|c|c|c|c|}
\hline \multirow{3}{*}{ Híbridos } & \multicolumn{15}{|c|}{ Épocas de semeadura } \\
\hline & \multicolumn{3}{|c|}{1} & \multicolumn{3}{|c|}{2} & \multicolumn{3}{|c|}{3} & \multicolumn{3}{|c|}{4} & \multicolumn{3}{|c|}{5} \\
\hline & PG & MMG & GA & PG & MMG & GA & PG & MMG & GA & PG & MMG & GA & PG & MMG & GA \\
\hline C 806 & 2.823 & 248 & 2,07 & 2.023 & 290 & 2,50 & 2.920 & 323 & 1,37 & 1.445 & 291 & 2,75 & 284 & 277 & 3,00 \\
\hline FT 9043 & 2.662 & 248 & 2,00 & 1.478 & 248 & 1,75 & 2.217 & 305 & 1,12 & 2.007 & 284 & 2,95 & 560 & 251 & 2,02 \\
\hline AG 5011 & 3.235 & 250 & 1,50 & 1.369 & 251 & 1,37 & 2.805 & 286 & 2,00 & 2.681 & 272 & 2,80 & 939 & 247 & 2,82 \\
\hline C 435 & 2.673 & 237 & 1,75 & 1.241 & 270 & 1,37 & 2.458 & 291 & 1,50 & 2.715 & 291 & 1,00 & 210 & 241 & 1,50 \\
\hline C 701 & 2.485 & 295 & 2,00 & 1.530 & 297 & 2,07 & 1.956 & 315 & 1,62 & 2.029 & 283 & 2,50 & 176 & 268 & 3,37 \\
\hline Médias & 2.775 & 255 & 1,86 & 1.528 & 271 & 1,81 & 2.741 & 304 & 1,52 & 2.175 & 284 & 2,40 & 434 & 257 & 2,54 \\
\hline C.V. (\%) & 8,87 & 5,29 & 13,17 & 10,46 & 5,93 & 20,61 & 15,02 & 3,75 & 12,34 & 21,78 & 4,55 & 33,29 & 21,82 & 6,33 & 10,96 \\
\hline
\end{tabular}

Época 1 =6/2/1997; Época 2 = 21/2/1997; Época 3 = 8/3/1997; Época 4 = 28/3/1997; Época 5 = 8/4/1997 
zando-se como os períodos de maior sensibilidade ao déficit hídrico.

Com relação à variável massa de mil grãos (MMG), os híbridos apresentaram comportamento cúbico nas regressões, no decorrer das cinco épocas de semeadura (Quadro 2). Os híbridos C 701 e C 806 foram os genótipos que manifestaram as maiores médias de MMG nos diferentes períodos estudados. A variável MMG manteve padrão de semelhança com a variável $P G$, visto que ambas tiveram comportamento cúbico em função da época de semeadura. Estes resultados são similares aos obtidos por NolDIN (1985), ao avaliar híbridos de milho em duas épocas de semeadura, no período de verão, no Rio Grande do Sul.

Para a variável percentagem de grãos ardidos (GA), os híbridos C 435 e C 701 não apresentaram diferenças significativas quanto à época de semeadura. As maiores médias de GA para os cinco híbridos avaliados foram obtidas na quinta época de semeadura (Quadro 2).

As estimativas das médias gerais dos híbridos e dos parâmetros de estabilidade de Plaisted e Peterson (1959) e Lin e BinNs (1988) encontram-se no quadro 3. Pelo primeiro método, observou-se que os híbridos FT 9043 e C 701 foram os mais estáveis, ou seja, apresentaram $\theta_{i}$ mais baixos, porém obtiveram as menores médias na produtividade geral. Pode-se notar que a produção média dos híbridos foi inferior à produção média do ensaio $\left(1.877 \mathrm{~kg} \cdot \mathrm{ha}^{-1}\right)$. Entre os cinco híbridos estudados, os mais instáveis foram $\mathrm{C}$ 806 e C 435, que apresentaram médias de produção de 1.899 e de $1.859 \mathrm{~kg} . \mathrm{ha}^{-1}$ respectivamente.

O híbrido que efetivamente apresentou a produção acima da média geral do ensaio foi o AG 5011
(Quadro 3), classificado como de estabilidade intermediária, pelo método de Plaisted e Peterson (1959). Pode-se notar que não houve coincidência entre materiais produtivos e estáveis, e observa-se que os híbridos mais produtivos apresentaram resultados inferiores de estabilidade. Estes são semelhantes àqueles encontrados por VERONESI (1995), ao avaliar genótipos de milho no Estado de Minas Gerais.

KANG (1988) desenvolveu metodologia para encontrar genótipos produtivos e estáveis, uma vez que os métodos com base em análise de variância utilizados não apontavam claramente a variabilidade do germoplasma. Os resultados são apresentados no quadro 3, podendo-se visualizar que o genótipo AG 5011 apresentou-se estável e produtivo.

Em relação ao método empregado por LiN e BinNs (1988), a expressão que estima o $P_{i}$, significa que, quanto menor o seu valor, menor será também o desvio em torno da produtividade máxima em cada ambiente. Assim, maior estabilidade estará obrigatoriamente associada à maior produtividade. Observase, ainda no quadro 3, que o híbrido AG 5011 apresentou o menor valor de $\mathrm{P}_{\mathrm{i}}(44,21)$ e maior produtividade (2.206 kg.ha- $\left.{ }^{-1}\right)$, sendo sua contribuição para a interação de apenas 15,60\% (3), considerada intermediária.

Para o híbrido C 806, a obtenção do maior valor de $P_{i}$, contribuindo com $55,77 \%$ (5), do valor devido à interação, sugere que esse material teve contribuição decisiva para a interação e indica a sua instabilidade, embora tenha apresentado a segunda maior média de produtividade.

Em resumo, o híbrido AG 5011 apresentou-se estável e produtivo pelos métodos de KANG (1988) e LiN e BinNs (1988), com estabilidade intermediária

Quadro 3. Médias gerais da produtividade $\left(\mathrm{kg}_{\mathrm{h}} \mathrm{ha}^{-1}\right)$ dos híbridos e estimativa dos parâmetros de estabilidade fenotípica pelos

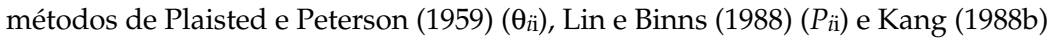

\begin{tabular}{|c|c|c|c|c|c|c|c|}
\hline \multirow{2}{*}{ Híbridos } & \multirow{2}{*}{$\begin{array}{l}\text { Produtividade } \\
\text { Média geral }\end{array}$} & \multirow{2}{*}{$\theta_{i}$} & \multirow{2}{*}{$\begin{array}{l}\text { Soma de ranks } \\
\text { Rank da produtividade + } \\
\text { rank de } \theta_{i}\end{array}$} & \multirow{2}{*}{$P_{i} / 1000$} & \multicolumn{2}{|c|}{ Desvio } & \multirow{2}{*}{$\begin{array}{c}\text { Contribuição } \\
\text { para a } \\
\text { interação }\end{array}$} \\
\hline & & & & & Genético & Interação & \\
\hline & kg.ha ${ }^{-1}$ & $\%$ & & & & & $\%$ \\
\hline C 806 & $1.899(2)^{*}$ & $35,43(5)^{*}$ & 7 & $221,17(4)^{*}$ & 109,23 & 111,97 & $55,77(5)$ \\
\hline C 435 & $1.859(3)$ & $21,11(4)$ & 7 & $167,22(2)$ & 128,52 & 38,74 & $19,28(4)$ \\
\hline AG 5011 & $2.206(1)$ & $17,85(3)$ & 4 & $44,21(1)$ & 12,90 & 31,31 & $15,60(3)$ \\
\hline C 701 & $1.635(5)$ & $13,72(2)$ & 7 & $278,76(5)$ & 267,33 & 11,43 & $5,71(2)$ \\
\hline FT 9043 & $1.785(4)$ & $11,87(1)$ & 5 & $176,44(3)$ & 169,13 & 7,32 & $3,64(1)$ \\
\hline Média geral & 1.877 & & & & & & \\
\hline
\end{tabular}

*Classificação de valores. 
entre os cinco híbridos avaliados e a maior média de produtividade de grãos $\left(2.206 \mathrm{~kg} \cdot \mathrm{ha}^{-1}\right)$.

\section{Referências Bibliográficas}

CORRÊA, L.A.; CRUZ, J.C.; FILHO, I.A.P. Avaliação de cultivares de milho para a 'safrinha' na Região CentroSul em 1996. In: SEMINÁRIO SOBRE A CULTURA DO MILHO 'SAFRINHA', 4., 1997, Assis. Resumos... Assis: IAC/CDV, p.135-139, 1997.

COSTA, A.F.S. Influência das condições climáticas no crescimento e desenvolvimento de plantas de milho (Zea mays L.), avaliadas em diferentes épocas de plantio. Viçosa, 1994. $109 \mathrm{p}$. Tese (Doutorado)-Universidade Federal de Viçosa.

DURÃES, F.O.M. Fatores ecofisiológicos afetando o comportamento de milho em semeadura tardia (safrinha) no Brasil Central. Piracicaba, 1993. 86p. Tese (Doutorado)-Escola Superior de Agricultura Luiz de Queiroz-USP.

GERAGE, A.G.; BIANCO, R.; NAZARENO, N.R.X.; GOMES, J.; OLIVEIRA, E.L.; KARAZAVA, M. Avaliação estadual de cultivares de milho. Londrina: IAPAR, 1984. 31p. (Informe de Pesquisa, 55).

GOMES, J. Parâmetros ambientais e época de semeadura. In: A cultura do milho no Paraná. Londrina: IAPAR, 1991. p.53-60. (Circular, 68).

GOMES, F.P. Curso de estatística experimental. 13.ed. Piracicaba: Nobel, 1990. 401p.

HUEHN, M. Nonparametric measures of phenotypic stability. Part 1: Theory. Euphytica, Dordrecht, v.47, p.89-94, 1990.

KANG, M.J. A rank-sum method for selecting high-yielding, stable corn genotypes. Cereal Research Communications, Szeged, v.16, p.113-115, 1988.

LIN, C.S.; BINNS, M.R. A superiority measure of cultivar performance for cultivar $x$ location data. Canadian Journal of Plant Science, Ottawa, v.68, p.193-198, 1988.
MIRANDA FILHO, J.B. Melhoramento do milho visando à tolerância ao frio. In: SEMINÁRIO SOBRE A CULTURA DO MILHO 'SAFRINHA', 3., 1995, Assis. Resumos... Assis: IAC/SEAB, 1995. p.49-58.

NOLDIN, J.A. Rendimento de grãos, componentes de rendimento e outras características de planta de três cultivares de milho em duas épocas de semeadura. Porto Alegre, 1985. 134p. Tese (Mestrado)-Universidade Federal do Rio Grande do Sul.

PLAISTED, R.L.; PETERSON, L.C. A technique for evaluating the ability of selection to yield consistency in different locations or seasons. American Potato Journal, Orono, v.36, p.381-385, 1959.

SHUKLA, G.K. Some statistical aspects of partitioning genotype-environmental components of variability. Heredity, Harlow, v.29, p.237-245, 1972.

SOUZA, F.R.S. Estabilidade de cultivares de milho (Zea mays L.) em diferentes épocas e locais de plantio em Minas Gerais. Lavras, 1989. 64p. Dissertação (Mestrado) - Escola Superior de Agricultura de Lavras.

TOLLENAAR, M.; DAYNARD, T.B.; HUNTER, R.B. Effect of temperature on rate of leaf appearence and flowering date in maize. Crop Science, Madison, v.19, p.363366, 1979.

TOMMASELLI, J.T.G.; VILLANOVA, N.A. Deficiência hídrica no solo e época de semeadura de milho (Zea mays L.) e seus efeitos sobre a produção em LondrinaPR. Revista Brasileira de Agrometeorologia, Santa Maria, v.2, p.69-75, 1994.

VERONESI, J.A. Comparação de métodos e avaliação da adaptabilidade e estabilidade de comportamento de vinte genótipos de milho (Zea mays L.) em dez ambientes do Estado de Minas Gerais. Viçosa, 1995. 84p. Tese (Mestrado)-Universidade Federal de Viçosa.

WARRINGTON, I.J.; KANEMASU, E.T. Corn growth response to temperature and photoperiod. II. Leaf-initiation and leaf-appearance rates. Agronomy Journal, Madison, v.75, p.755-761, 1983. 